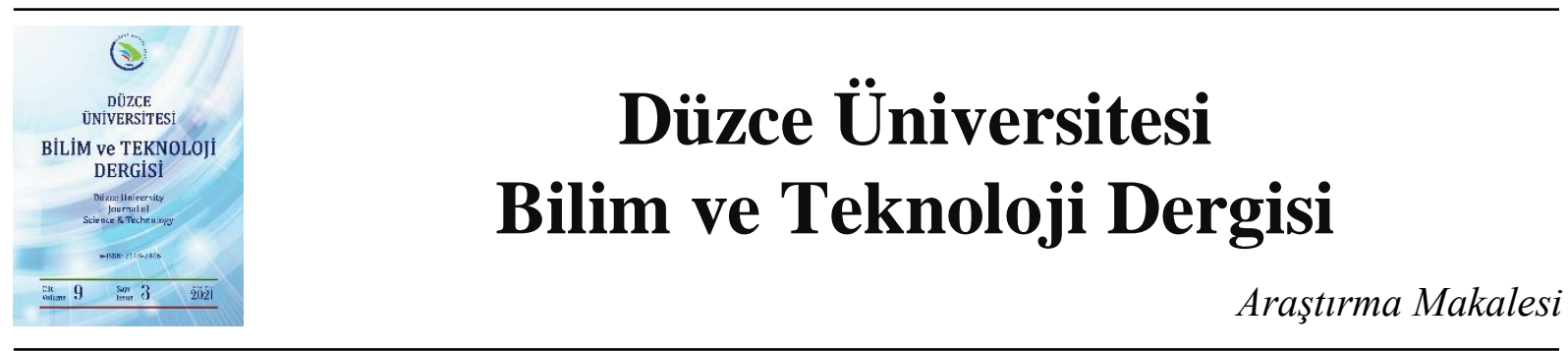

\section{Pürüzlülük Katsayısının Açık Kanal Akımına Etkisinin İncelenmesi}

\author{
(D) Gökçen ERYILMAZ TÜRKKAN ${ }^{\mathrm{a}, *}$ \\ a İnşaat Mühendisliği Bölümü, Mühendislik Fakültesi, Bayburt Üniversitesi, Bayburt, TÜRKIYE \\ * Sorumlu yazarin e-posta adresi: geryilmazturkkan@bayburt.edu.tr
}

DOI: 10.29130/dubited.800691

\begin{abstract}
ÖZET
Dünyamızda küresel ısınmanın etkisi ile deniz seviyesinin yükselmesi, mevsimlerin değişmesi ve ekosistemin bozulması sonucu taşkınlar meydana gelebilmektedir. Taşkınları önlemek için iyi bir planlama ve projelendirme gerekmektedir. Bu çalışma ile pürüzlülük katsayısının açık kanal akımına etkisi araştırılmışıı. Çalışmada amaç, mevsimsel değişim sonucu bitki örtüsünün değişmesine bağlı olarak kanaldaki akımı incelemektir. Bu çalışma, Bayburt il sınırları içerisinde kalan Sarıhan deresi üzerinde gerçekleştirilmiştir. Farklı pürüzlülük katsayıları kullanılarak akım durumları modellenmiştir. Çalışmada, sayısal modeli oluşturabilmek için ArcGIS ve HecGeoRAS yazılımları kullanılmıştır. Açık kanal akımını modellemek için ise HEC-RAS yazılımı tercih edilmiştir. Pürüzlülük katsayısının değişmesiyle birlikte kesit için froude sayısı, enkesit hızları ve buna bağlı olarak su seviyesi ve akış alanının değiştiği görülmüştür. Ayrıca çalışmada hesaplanan 4 farklı pürüzlülük katsayısı değeri için, Sarıhan nehrinin herhangi bir kesiminde su baskınına neden olacak kritik akış hızları belirlenmiştir. Çalışmada, mevsimsel değişimler sonucu değişen pürüzlülük katsayısının önemi model ile vurgulanmıştır.
\end{abstract}

Anahtar Kelimeler: Mevsimsel değişim, Taşkin, ArcGIS, HEC-RAS, Bayburt

\section{Investigation of the Roughness Coefficient Effect on Open Channel Flow}

\begin{abstract}
With the effect of global warming in our world, rising sea levels, changing seasons and degrading the ecosystem can cause floods. Preventing floods requires good planning and projecting. The effect of roughness coefficient on open channel flow was investigated with this study. The purpose of the study is to examine the flow in the channel depending on the seasonal change of vegetation cover. This study was carried out on the Sarihan river, which is located within Bayburt province borders. The flow was simulated using different roughness coefficients. In the study, ArcGIS and Hec-GeoRAS software were used to create a numerical model. HEC-RAS software was preferred to simulate open channel flow. The froude number, velocities in the cross section, the water level and the flow area have been seen to differences with the change of the roughness coefficient. In addition, for four different roughness coefficient values calculated in the study, critical flow rates that will cause flooding in any section of Sarihan river were determined. In this study, the importance of roughness coefficient, which changes as a result of seasonal changes, was emphasized with this model.
\end{abstract}

Keywords: Seasonal change, Flood, ArcGIS, HEC-RAS, Bayburt

Geliş: 27/09/2020, Düzeltme: 27/12/2020, Kabul: 13/01/2021 


\section{GIRIS}

Taşkınlar gerçekleştiği bölgede ekonomik ve sosyal faaliyetleri kesintiye uğratan doğal bir olaydır. Taşkın risklerine maruz kalan insan sayısının, 2050 yılında 1.6 milyara yükseleceği tahmin edilmektedir [1]. Oluşabilecek taşkınları ve akabinde oluşacak olumsuz durumların önüne geçebilmek için tasarım oldukça önemlidir. Dere 1slahı ve taşkın önleme çalışmaları gerçekleştirilirken tasarımda yüzeyde hangi malzemenin kullanılacağı tasarımı etkilen önemli etkenlerden biridir. Açık kanal akımlarında, akımın modellenebilmesi için yüzey pürüzlülüğünün bilinmesi gerekmektedir. Kanal debisi hesaplanırken kanalın hidrolik yarıçapı, kanal eğimi belirlenir ve yüzey pürüzlülük katsayısı seçilerek hesaplar yapılır. Kullanılan malzeme bilindiği için yapay kanallarda pürüzlülük katsayısının seçimi daha kolaydır. Kanal kaplamasına bağlı olarak bir değer seçilebilir.

Bu çalışma ile pürüzlülük katsayısının önemine değinilmek istenmiştir. Kurak mevsimde kuruyan otlar sulak mevsimde ise boy verip uzayacaktır. Farklı iklim, mevsim koşulları altında bitki örtüsünün yoğun olması ya da olmaması durumları için farklı pürüzlülük katsayıları söz konusudur. Çalışmada, mevsimsel değişim sonucu bitki örtüsünün değişmesine bağlı olarak farklı pürüzlülük katsayıları için serbest yüzeyli akımlarda oluşabilecek akım durumları incelenmiştir. Bayburt ili merkez ilçesine bağlı olan Sarıhan köyünden geçen Sarıhan deresinin farklı pürüzlülük katsayıları ile akım durumları modellenmiştir. Çalışmada, sayısal modeli oluşturabilmek için ArcGIS ve Hec-GeoRAS yazılımları kullanılmıştır. Açık kanal akımı ise HEC-RAS yazılımı ile çözülmüştür. Arazinin topoğrafik verileri için arazi çalışması gerçekleştirilmiştir. Sarıhan deresi ve civarında birçok kot ölçümü alınarak çalışma alanının topoğrafik verileri elde edilmiştir. Topoğrafik veriler ArcGIS ortamında işlenmiş, dere yatağı ve civarındaki tüm yükseklikler TIN formatına dönüştürülmüştür. Dere profili ve enkesitleri HecGeoRAS ile üretilmiş Hec-RAS programına iletilmiştir. Dere, sabit bir debi değeri altında farklı pürüzlülük katsayı değerleri ile HEC-RAS'da modellenmiştir. Buna ek olarak hesaplanan farklı pürüzlülük katsayı değerleri için Sarıhan deresinin herhangi bir kesitinde taşkına sebep olacak kritik debi değerleri de belirlenmiştir.

Literatürde taşkınlar ve pürüzlülük katsayısı ile ilgili birçok çalışma mevcuttur. Bu çalışmaları şu şekilde sıralayabiliriz: Üyüklüoğlu vd. [2] çalışmalarında Antalya - Manavgat'ta bulunan Ilıca Deresinde HECRAS programıla su yüzü profilini modellemiştir. Bulu ve Yılmaz [3] çalışmalarında açık kanal akımlarında pürüzlülük katsayısını incelemiştir. Horritt ve Bates [4] çalışmalarında taşkınları tahmin etmek için $1 \mathrm{~B}$ ve 2B sayısal model değerlendirmesi gerçekleştirmiştir. Özdemir [5] çalışmasında taşkınların haritalandırılmasında Hec-GeoRAS ve Hec-RAS'ı kullanmıştır. Dursun [6] Murat nehri civarında taşkın seviyesinin belirlenmesi üzerine bir çalışma gerçekleştirmiştir. Bales ve Wagner [7] hidrolik model geliştirme ve doğrulama için kullanılan hidrolojik verileri, topografik verileri ve hidrolik modeli içeren bir çalışma gerçekleştirmiştir. Baldassarre vd. [8] eğim yükselmesinin taşkın yayılması üzerindeki etkilerini analiz etmiştir. Özcan vd. [9] taşkın alanlarının CBS ve UA yardımıyla belirlenmesi üzerine bir çalışma gerçekleştirmiştir. Biondi ve De Luca [10] gerçek zamanlı taşkın tahmini için BFS değerlendirmesi yapmıştır. Nas ve Nas [11] taşkın alanlarının coğrafi bilgi sistemleri yardımıyla belirleyip risk analizi gerçekleştirmiştir. Doğan vd. [12] çalışmalarında aşağı Sakarya nehri için taşkın yayılım haritalarını çıkarmıştır. Yerdelen vd. [13] akış kesitinde oluşacak direnç kuvvetinin, bitkilerin ve akışın fiziksel şartlarına bağlı olarak nasıl değiştiği incelemiştir. Efe ve Önen [14], çalışmalarında Batman Çayı'nın Yeni Malabadi Köprüsü ile Diyarbakır - Batman Karayolu Köprüsü arasında kalan kesimine ait taşkın analizi gerçekleştirmiştir. Ibrahim ve Abdel-Mageed [15] çalışmalarında yatak pürüzlülüğünün akış özelliklerine etkisini incelemiştir. Ercan vd. [16] çalışmalarında Kahramanmaraş ilinin On iki Şubat ilçe merkezindeki kuşaklama kanalı projesinin hesaplarını, HEC-RAS programı ile modelleyip sonuçları karşılaştırmıştır. Ogras ve Onen [17] çalışmalarında Dicle Nehri Rehabilitasyon Projesi'ne katkıda sağlamak amacıyla Dicle Nehri'nin yinelenen ve tek boyutlu taşkın yatağı analizlerini gerçekleştirmiş̧ir. 


\section{MATERYAL ve YÖNTEM}

Coğrafi bilgi sistemlerinde (CBS) topografik veriler Türkiye'de uydu fotoğraflarından, Harita Genel Komutanlığından veya özel çalışmalarla hazırlanan yüksek hassasiyetli haritalardan elde edilebilir. $\mathrm{Bu}$ haritalar yardımıyla havzaya ait sayısal yükseklik modeli oluşturulur. Aslında sayısal yükseklik modeli, hava fotoğraflarından otomatik eşlemeyle üretilmiş olan arazi topoğrafyasındaki tüm detayları kapsayan \pm 3 m düşey doğruluklu yükseklik verisidir. Sayısal yükseklik modeli (Digital Elevation Models-DEM) olarak adlandırılan haritaların elde edilebilmesi için de havzanın üç boyutlu arazi modeli yani TIN haritaları elde edilmelidir. TIN, üçgen modelleme yoluyla doğrudan topografik verilerden elde edilir, TIN oluşturulurken girdi noktaları üçgenlerin köşeleri olur. Köşeler üçgenlerin kenarlarını oluşturacak çizgiler ile bağlanır. Sonuç olarak köşelerden ve kenarlardan oluşan sürekli bir üçgenler yüzeyi elde edilir. DEM ise, TIN' i veri olarak kullanarak oluşturulan arazi modeli türüdür [18].

Hec-GeoRAS [19], HEC-RAS [20] programı için tasarlanmış bir CBS arayüzüdür. HEC-GeoRAS; HEC-RAS ve ArcGIS arasında geçişi sağlar. HEC-RAS ise tek boyutlu hidrodinamik hesapları yapabilecek şekilde oluşturulmuştur. Program; her tür akım için hesap yapabilmektedir. Bu çalışmada ise sayısal modeli oluşturabilmek için ArcGIS ve Hec-GeoRAS yazılımları kullanılmış, açık kanal akımı için ise HEC-RAS yazılımı tercih edilmiştir.

HEC-RAS kararlı, kararsız akım durumları ve kritik altı akım, kritik üstü akım veya karışık akım şartları altında su yüzü profilini belirlenmede kullanılır. Program, kararlı akım şartlar altında yapılan çözümlerde, tek boyutta enerji denklemini temel alınmaktadır. Momentum denklemi ise, akım rejiminin ani değiştiği durumlarda kullanılmaktadır. [21]. HEC-RAS yazılımı aynı zamanda momentum, WSPRO ve Yarnell yöntemlerini de desteklemektedir. Bu basit yöntem, enerji denklemi çözüme dayanır. U.S. Army Corps of Engineers tarafından geliştirilmiş olan HEC-RAS standart adım yöntemini kullanmaktadır. Bu yöntemde kanaldaki iki en kesit arasında enerji denklemi ile iterasyon yapılarak su yüzü profili hesabı yapılır. Standart adım yöntemi yavaş değişen akımların başlangıcında, sonunda veya herhangi iki yerinde oluşan $h$ akım derinliklerinden bir tanesinin ve yatay mesafesinin bilinmesi durumunda, diğer akım derinliğinin hesaplanması için kullanılmaktadır. Ayrıca sonlu farklar yönteminden farklı olarak su derinliğinin hesabı deneme yanılma yöntemi ile belirlenmektedir.

\section{CALISMA BÖLGESİ ve VERILLER}

Bayburt ili $40^{\circ} 37^{\prime}$ kuzey enlemi ile $40^{\circ} 45^{\prime}$ doğu boylamı, $39^{\circ} 52^{\prime}$ dakika güney enlemi ile $39^{\circ} 37^{\prime}$ bat1 boylamları arasında yer alır. [22]. Sarıhan Köyü ise Bayburt ili merkez ilçesine bağlıdır. (Şekil 1). 


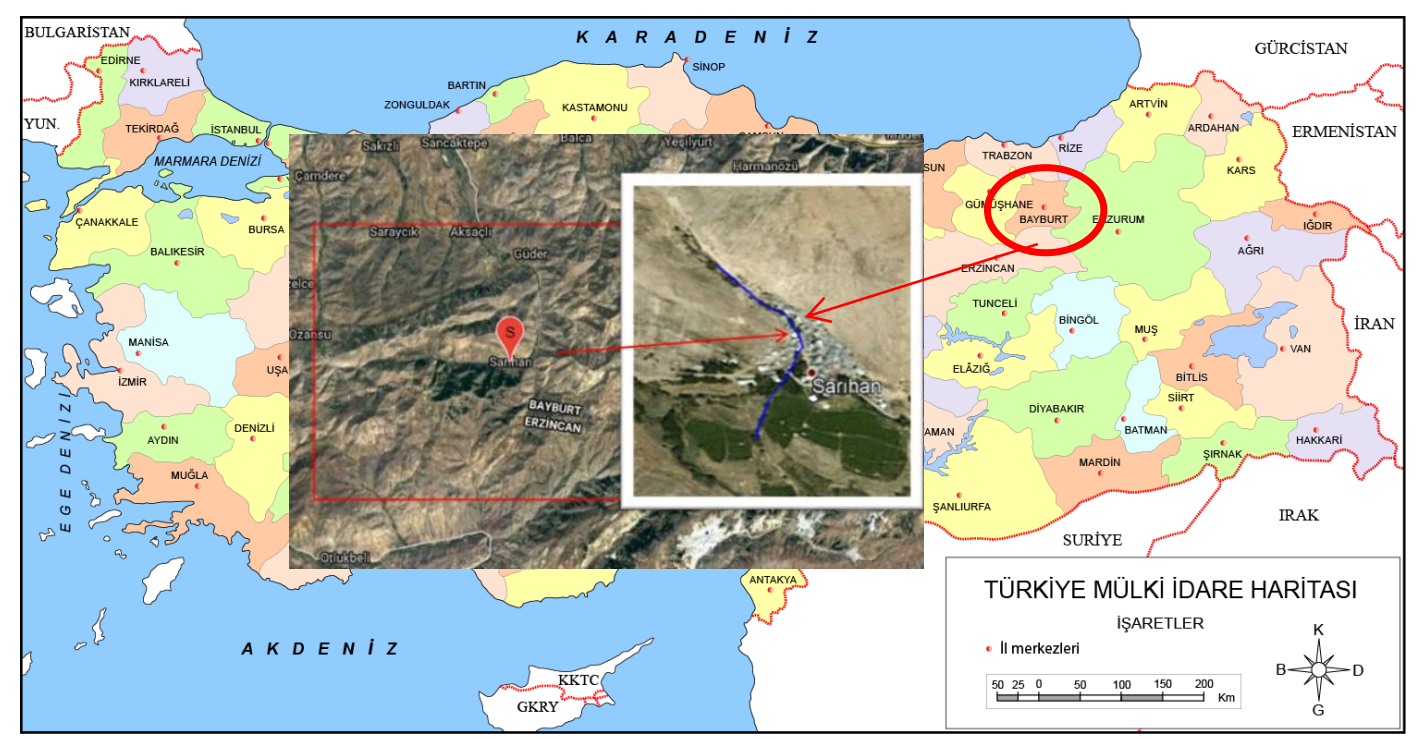

Şekil 1. Çalışma alanı

Çalışma alanına ait sayısal yükseklik modelinden TIN modeline geçiş yapabilmek için ArcToolbox'ın 3D Analyst Tools modülü kullanılmıştır. Topoğrafik verilerin oluşturulmasında ana veri tabanı olarak TIN kullanılmıştır. Sarıhan deresi için oluşturulan TIN formatından HEC-RAS girdi verileri yani çalışma sahasına ait topoğrafik veriler HEC-GeoRAS ile üretilip tamamlanmışır. Derenin çalışılan kısmı için topoğrafik değişimlere bağlı olarak toplamda 8 adet enkesit alınmıştır. Her bir enkesitin uzunluğu 90 metre olarak seçilmiştir. Enkesitler arası mesafe yaklaşık 500 metre civarındadır. Sarıhan deresinin bu çalışmada çalışılan kısmı toplamda 3500 m civarındadır. Akım şartlarının düzenlenmesi ve akım analizi için HEC-RAS kullanılmıştır. Import işlemi tamamlandıktan sonra dereye ait geometrik veriler HEC-RAS programına aktarılmıştır.

Şekil 2'de dere profilinin memba ve mansap kısımlarına yer verilmiştir. HEC-RAS'da çözümü gerçekleştirebilmek için tanımlanması gereken sınır koşulu olarak ise eğim belirlenmiştir. Eğimler ise memba tarafında alınan ve mansap tarafinda alınan ardışı iki kesit kullanılarak hesaplanmıştır. HECRAS programında derenin profilinden faydalanılarak kanalın eğimi, memba kısmında $S=0.003$ mansap kısmında ise $S=0.006$ olarak hesaplanıp, kanal yukarı ve aşağı yönde hesaplanan aynı eğimlerle sonsuza kadar uzanıyormuş gibi düşünülerek hem akış yukarısında hem de akış aşağısındaki kısımlarda normal derinlik sınır koşulu tanımlanmıştır. Akım rejimi karışık olarak seçilerek kararlı durum için modelleme yapılmıştır. Her bir modellemede için debi değeri, herhangi bir kesitte taşkına sebep olmayacak şekilde $\mathrm{Q}=10 \mathrm{~m}^{3} / \mathrm{sn}$ olarak alınmıştır.

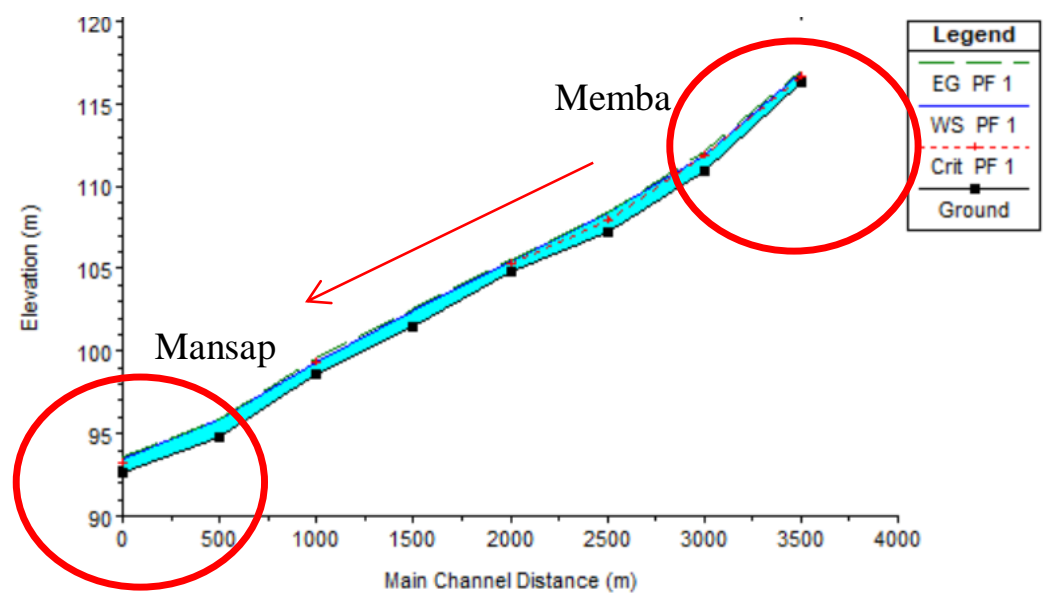

Şekil 2. HEC-RAS dere profili 


\section{BULGULAR ve TARTISMA}

Pürüzlülük katsayısını yüzey pürüzlülüğü, bitki örtüsü gibi etkileyen birtakım etmenler vardır. Kanaldaki bitki örtüsü pürüzlülük katsayısı seçiminde önemli bir etkendir. Bölgedeki mevsimsel değişim sonucu bitki örtüsünün değişmesiyle pürüzlülük katsayısı da değişir. Pürüzlülük katsayısı aynı kesit için farklı mevsimlerde çok farklı değerler almaktadır. Bu çalışmada, çalışılan doğal kanalda sadece bitki örtüsünün değişiminin kanalda oluşturacağı etki incelenmiştir. Bu amaçla, farklı yüzey pürüzlülükleri için 4 adet modelleme HEC-RAS' da gerçekleştirilmiştir.

Devlet Su İşleri (DSİ) ülkemiz için pürüzlülük katsayısının belirlenmesinde en uygun yöntemin Cowan yöntemi olduğunu düşünmektedir. [23]. Yöntem W. L. Cowan [24] tarafından geliştirilmiştir (Eşt. 1).

$$
n=\left(n_{o}+n_{1}+n_{2}+n_{3}+n_{4}\right) m
$$

n pürüzlülük katsayısı iken, $\mathrm{n}_{0}$ katsayısı kanalın geçtiği zeminin özelliğine bağlı olarak belirlenen pürüzlülük katsayısıdır. $\mathrm{n}_{1}$, kanal düzensizliğini içeren düzeltme katsayısıdır. $\mathrm{n}_{2}$, kanal kesitinin şekil ve boyutundaki değişmeyi içeren düzeltme katsayısı iken, $\mathrm{n}_{3}$ kanaldaki mevcut engelleri içeren düzeltme katsayısıdır. $\mathrm{n}_{4}$ seçiminde ise kanal içindeki bitki örtüsünün etkisi dikkate alınır. m katsayı ise kanaldaki mendereslenme (kıvrım) düzeyine bağlı olarak belirlenir. Bu değerlerin hepsine Tablo 1'de yer verilmiştir.

Tablo 1. Kanal koşullarına bağlı belirlenen pürüzlülük değerleri [3], [24]

\begin{tabular}{|c|c|c|c|}
\hline Kanal Koşulları & & De & \\
\hline \multirow{4}{*}{ Kanalın içerdiği malzeme } & Toprak & \multirow{4}{*}{$\mathbf{n}_{\mathbf{0}}$} & 0.020 \\
\hline & Kaya & & 0.025 \\
\hline & Kum & & 0.024 \\
\hline & Çakıl & & 0.028 \\
\hline \multirow{4}{*}{ Düzensizlik derecesi } & Pürüzsüz & \multirow{4}{*}{$\mathbf{n}_{1}$} & 0 \\
\hline & Önemsiz & & 0.005 \\
\hline & Orta & & 0.010 \\
\hline & Şiddetli & & 0.020 \\
\hline \multirow{3}{*}{ Kanal yarıçapındaki değişimler } & Aşamalı & \multirow{3}{*}{$\mathbf{n}_{2}$} & 0 \\
\hline & Ara sira değișen & & 0.005 \\
\hline & S1k değişen & & $0.010-0.015$ \\
\hline \multirow{4}{*}{ Engellerin benzer etkileri } & İhmal edilebilir & \multirow{4}{*}{$\mathbf{n}_{3}$} & 0 \\
\hline & Önemsiz & & $0.010-0.015$ \\
\hline & Kayda değer & & $0.020-0.030$ \\
\hline & Şiddetli & & $0.040-0.060$ \\
\hline \multirow{4}{*}{ Bitki örtüsü } & Düşük & \multirow{4}{*}{$\mathbf{n}_{4}$} & $0.005-0.010$ \\
\hline & Orta & & $0.010-0.025$ \\
\hline & Yüksek & & $0.025-0.050$ \\
\hline & Çok yüksek & & $0.050-0.100$ \\
\hline \multirow{3}{*}{ Kıvrım derecesi } & Önemsiz & \multirow{3}{*}{$\mathbf{m}$} & 1.00 \\
\hline & Kayda değer & & 1.15 \\
\hline & Şiddetli & & 1.30 \\
\hline
\end{tabular}

$\mathrm{Bu}$ çalışmada çalış1lan arazi durumu göz önüne alınarak $\mathrm{n}_{0}=0.02 \mathrm{n}_{1}=0.01 \mathrm{n}_{2}=0.005 \mathrm{n}_{3}=0 \mathrm{~m}=1$ alınmıştır. Bitki örtüsünün farklılığ 1 incelenmek istendiğinden $\mathrm{n}_{4}$ ifadesi için 4 farklı değer alınarak çalışma yürütülmüştür.

1.modelleme için Tablo 1 'de geçen $\mathrm{n}_{4}=0.010$ değeri, 2 . modelleme için $\mathrm{n}_{4}=0.025$ değeri, 3 . modelleme için $\mathrm{n}_{4}=0.050$ değeri, 4 . modelleme $\mathrm{n}_{4}=0.100$ değeri seçilmiştir. 
Eşt. 1 kullanılarak 1. modelleme için $n=0.045$ 2. modelleme için $n=0.0603$. modelleme için $n=0.085$ ve 4. modelleme için $n=0.135$ olarak hesaplanmıştır. Derenin çalışılan kısmı için topoğrafik değişimlere bağlı olarak toplamda 8 adet enkesit alınmıştır. Sınır koşulları tanımlanmış ve herhangi bir kesitte taşkına sebep olmayacak şekilde debi değeri $10 \mathrm{~m}^{3} / \mathrm{sn}$ olarak seçilmiştir. Modellemeler HEC-RAS programı ile gerçekleştirilmiştir. Tekrarı önlemek amacıyla memba kısmından alınan ilk kesit için modelleme sonuçları Tablo 2'de sunulmuştur. Ayrıca 4 farklı modelleme için de memba kısmından alınan ilk en kesitteki değişimi görebilmek adına HEC-RAS sonuçlarına yer verilmiştir (Şekil 3).

Bunlara ek olarak, hesaplanan 4 farklı n değeri için Sarıhan deresinin herhangi bir kesitinde taşkına sebep olacak kritik debi değerleri (sınır değer) de belirlenmiştir. 1. Modelleme için seçilen $\mathrm{n}$ değeri hesaplarda kullanıldığında kritik debinin $44 \mathrm{~m}^{3} / \mathrm{sn}$, 2. Modelleme için seçilen $\mathrm{n}$ değeri hesaplarda kullanıldığında kritik debinin $26 \mathrm{~m}^{3} / \mathrm{sn}, 3$. Modelleme için kritik debinin $19 \mathrm{~m}^{3} / \mathrm{sn}$, 4. Modelleme için de kritik debinin $12 \mathrm{~m}^{3} / \mathrm{sn}$ olduğu belirlenmiştir. Bu çalışmada bulunan sonuçlar literatürde yer alan çalışmalarla kıyaslanıp tartışıldığında tutarlı sonuçların elde edildiği düşünülmektedir.

Tablo 2. Ilk kesit için modelleme sonuçları

\begin{tabular}{ccccc}
\hline & $\begin{array}{c}\text { Pürüzlülük katsayısı } \\
(\text { Cowan }) \mathbf{n}\end{array}$ & Hız $(\boldsymbol{m} / \mathbf{s} \boldsymbol{n})$ & Froude sayısı & Akım alanı $\left(\boldsymbol{m}^{\mathbf{2}}\right)$ \\
\hline 1. modelleme & 0.045 & 0.91 & 0.44 & 10.97 \\
\hline 2. modelleme & 0.060 & 0.71 & 0.32 & 14.04 \\
\hline 3. modelleme & 0.085 & 0.59 & 0.24 & 17.09 \\
\hline 4. modelleme & 0.135 & 0.43 & 0.16 & 23.19 \\
\hline
\end{tabular}

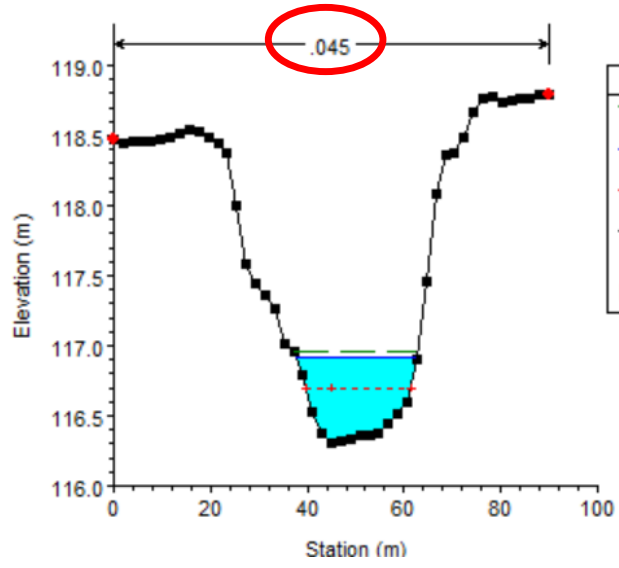

(a)

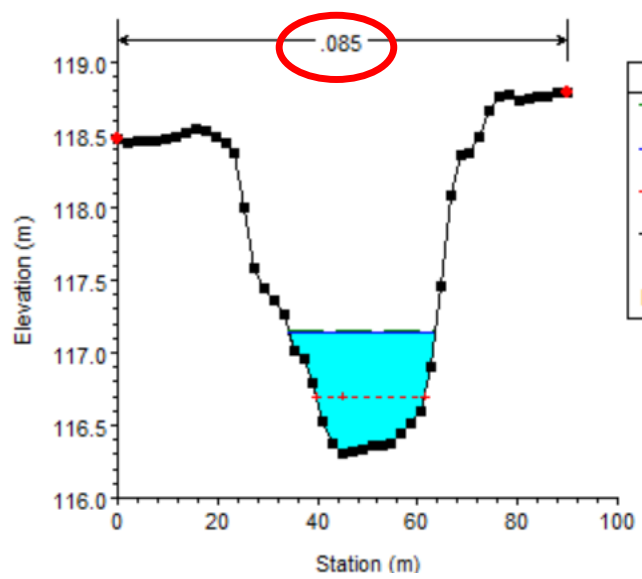

(c)

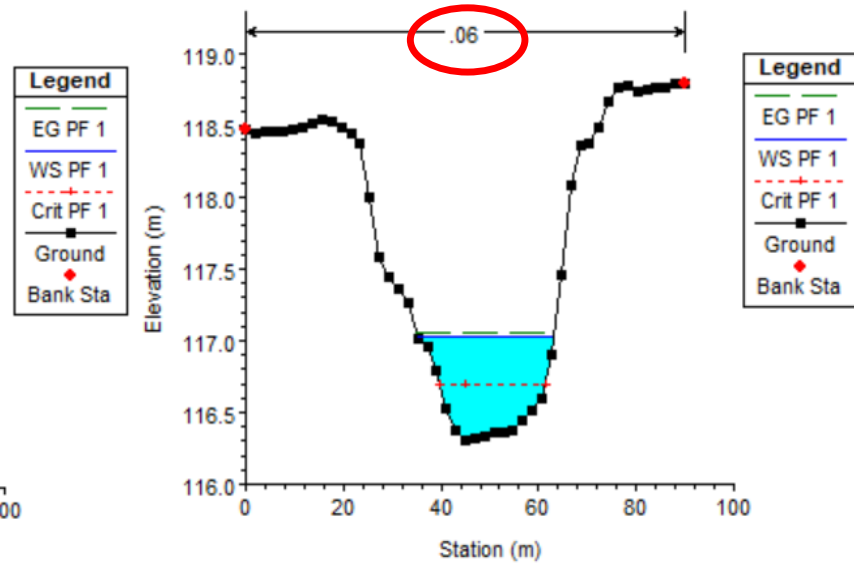

(b)
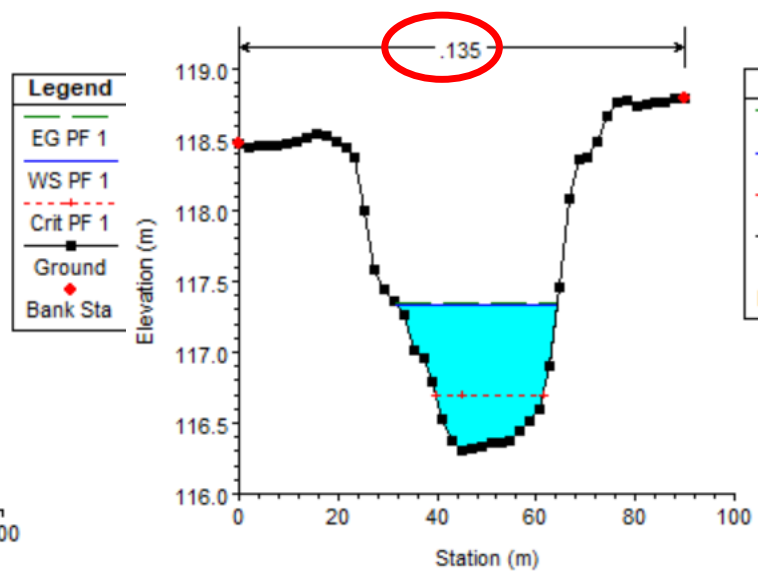

(d)

Şekil 3. Memba tarafindaki ilk kesitin HEC-RAS sonucu [(a) birinci modelleme için (b) ikinci modelleme için (c) üçüncü modelleme için $(\boldsymbol{d})$ dördüncü modelleme için 


\section{V.SONUCLAR}

Bu çalışmada, mevsimsel değişim ile birlikte bitki örtüsünün değişmesi sonucu farklı pürüzlülük katsayılarıyla serbest yüzeyli akımlarda oluşabilecek akım durumları incelenmiştir. Çalışmada, sayısal modeli oluşturabilmek için ArcGIS ve Hec-GeoRAS yazılımları kullanılmıştır. Toplamda 8 enkesit alınmıştır. Cowan yöntemi kullanılarak 4 farklı yüzey pürüzlülüğü hesaplanmıştır. Bu 4 farklı durum için açık kanal akımı HEC-RAS yazılımı ile modellenmiştir. 8 enkesitin tamamı, her bir modelleme için ayrı ayrı incelenmiştir.

Pürüzlülük katsayısı arttığında Froude sayısı azalmakta, enkesitlerdeki hızın azaldığı görülmekte ve buna bağlı olarak su seviyesinin arttığı aynı enkesit için akım alanının da arttığı görülmektedir. $\mathrm{Bu}$ çalışma ile mevsimsel değiş̧im sonucu değişen pürüzlülük katsayısının modellemedeki önemi göz önüne serilmiştir. Hızların oldukça değiştiği gözlenmektedir. Ayrıca çalışmada Hesaplanan 4 farklı n değeri için Sarıhan deresinin herhangi bir kesitinde taşkına sebep olacak kritik debi değerleri de belirlenmiştir. 1. Modelleme için kritik debinin $44 \mathrm{~m}^{3} / \mathrm{sn}, 2$. Modelleme için kritik debinin $26 \mathrm{~m}^{3} / \mathrm{sn}, 3$. Modelleme için kritik debinin $19 \mathrm{~m}^{3} / \mathrm{sn}$ ve 4 . Modelleme için de kritik debinin $12 \mathrm{~m}^{3} / \mathrm{sn}$ olduğu belirlenmiştir.

Özellikle taşkın kanalları modellenirken pürüzlülük katsayısının seçimi oldukça önemlidir. Pürüzlülük katsayısının doğru seçimi hızı ve kesitlerde oluşacak olan su seviyesini dolayısıyla taşkın durumunu etkileyecektir. Çok sayıda can kaybına ve büyük maddi hasarlara neden olan taşkınları önlemek, iyi bir planlama ve projelendirmeyi gerektirmektedir. Taşkınlardan korunmak adına doğru projelendirme oldukça önem arz etmektedir. Ayrıca taşkın önlem çalışmaları da sosyal açıdan halk da güven tahsis edilmesi bağlamında önemlidir.

\section{KAYNAKLAR}

[1] WWDR, "The United Nations World Water Development Report," Nature-Based Solutions for Water, Unesco, France, Rap. 7, 2018.

[2] M. Üyüklüoğlu, B. Ünal, B. Turan, "HEC-RAS paket programı ile Manavgat ilçesi Ilıca deresi taşkın bölgesinin modellenmesi," 4. Su Yapıları Sempozyumu, Antalya, Türkiye, 2015.

[3] A. Bulu, E. Yılmaz, "Serbest yüzeyli akımlarda pürüzlülük katsayısının belirlenmesi," Türkiye Mühendislik Haberleri, c. 47, s. 420-422, ss. 79-81, 2002.

[4] M.S. Horritt, P.D. Bates, "Evaluation of 1D and 2D numerical models for predicting river flood inundation," Journal of Hydrolog, c. 268, s. 1-4, ss. 87-99, 2002.

[5] H. Özdemir, "Taşkınların haritalanmasında Hec-GeoRAS ve Hec-RAS'ın kullanımı: Havran çayı örneği (Balıkesir)," TMMOB Harita ve Kadastro Mühendisleri Odası Ulusal Coğrafi Bilgi Sistemleri Kongresi, Trabzon, Türkiye, 2007.

[6] Ö. Dursun, "Murat nehrinin Elazığ ili palu ilçesi civarındaki taşkın seviyesinin belirlenmesi," Doğu Anadolu Bölgesi Araştırmaları, c. 7, s. 1, ss. 130-133, 2008.

[7] J.D. Bales, C.R.Wagner, "Sources of uncertainty in flood inundation maps," Journal of Flood Risk Management, c. 2, s. 2, ss. 139-147, 2009.

[8] G. Di Baldassarre, A. Castelların, A. Brath, "Analysis on the effects of levee heightening on flood propagation: example of the river Po, Italy," Hydrological Sciences Journal, c. 54, s. 6, ss. 10071017, 2009. 
[9] O. Özcan, N. Musaoğlu, D.Z. Şeker, "Taşkın alanlarının CBS ve UA yardımıyla belirlenmesi ve risk yönetimi; Sakarya havzası örneği," TMMOB Harita ve Kadastro Mühendisleri Odası 12. Türkiye Harita Bilimsel ve Teknik Kurultayl, Ankara, Türkiye, 2009.

[10] D. Biondi, D.L. De Luca, "Performance assessment of a bayesian forecasting system (BFS) for real-time flood forecasting," Journal of Hydrology, s. 479, ss. 51-63, 2013.

[11] S.S. Nas, E. Nas, "Taşkın alanlarının coğrafi bilgi sistemleri yardımıyla belirlenmesi ve risk analizi: Harşit çayı (Gümüşhane) örneği," Taşkın ve Heyelan Sempozyumu, Trabzon, Türkiye, 2013, ss 405-419.

[12] E. Doğan, O. Sönmez, E. Yapan, K. Othan, S. Özdemir, T. Çitgez, “Aşağı Sakarya nehrinde taşkın yayılım haritalarının elde edilmesi,” SAÜ. Fen Bil. Der., c. 17, s. 3, ss. 363-369, 2013.

[13] C. Yerdelen, M. Mertsoy, G. Tayfur, "Rijit gövdeli bitkilerin neden olduğu manning katsayısının araştırılması," IMO Teknik Dergi, c. 26, s. 2, ss. 7055-7076, 2015.

[14] H. Efe, F. Önen, "Batman çayı'nın taşkın analizinin HEC-RAS programıyla yapılması," Dicle Üniversitesi Mühendislik Fakültesi - Mühendislik Dergisi, c. 6, s. 2, ss. 83-92, 2015.

[15] M.M. Ibrahim, N.B. Abdel-Mageed, "Effect of bed roughness on flow characteristics," International Journal of Academic Research, c. 6, s. 5, ss. 169-78, 2014.

[16] B. Ercan, A. E. Yağc1, M. Ünsal, "Kahramanmaraş Domuz (Boğaz) Deresi Kuşaklama Kanalının HEC-RAS Modeli," Artvin Çoruh Üniversitesi Doğal Afetler Uygulama ve Araştırma Merkezi Doğal Afetler ve Çevre Dergisi, c. 5, s. 1, ss. 58-64, 2019.

[17] S. Ogras, F. Onen, "Flood Analysis with HEC-RAS: A Case Study of Tigris River," Advances in Civil Engineering, c. 2020, 2020, doi: 10.1155/2020/6131982

[18] İ. Uçar, "Trabzon değirmendere havzasında coğrafi bilgi sistemleri ve bir hidrolik model yardımıyla taşkın analizi yapılması," Yüksek lisans tezi, İnşaat Mühendisliği Anabilim Dalı, Fen Bilimleri Enstitüsü, Gazi Üniversitesi, Ankara, Türkiye, 2010.

[19] Anonim, "Hec-geoRAS Gis tools for support of Hec-RAS using Arc-GIS, User's Manual Version 4.2," US Army Corps of Engineers, Institute for Water Resources, Amerika, 2009.

[20] Anonim, "HEC-RAS River Analysis System" User's Manual 6.0 Beta," U.S. Army Corps of Engineers, Institute for Water Resources, Amerika, 2020.

[21] İ. Tuncer, "Açık Kanallarda Su Yüzü Profilinin Belirlenmesi, Nakkaş Dere Örneğinde Bir HECRAS Uygulaması," Yüksek lisans tezi, İnşaat Mühendisliği Anabilim Dalı, Fen Bilimleri Enstitüsü, Gazi Üniversitesi, Ankara, Türkiye, 2011.

[22] Anonim, "Bayburt ili 2015 y1l çevre durum raporu," Bayburt Çevre ve Şehircilik İl Müdürlüğü Çed ve Çevre Hizmetleri Şube Müdürlügü, Türkiye, 2016.

[23] Anonim, "Dere yatakları için pürüzlülük katsayısı belirleme kılavuzu," DSİ, Ankara, Türkiye, 2015.

[24] W. L. Cowan, "Estimating hydraulic roughness coefficients," Agricultural Engineering, c. 37, s. 7, ss. $473-475,1956$. 